Table I

Experimental Groups

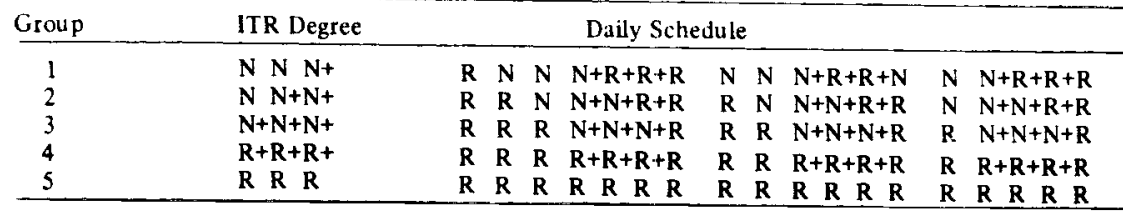

Note: The symbol $+=I T R$

tion except no food was available. Therefore, Ss received nonreinforced placements (ITN) in the extinction schedule where ITR had occurred during acquisition.

\section{RESULTS}

Individual median starting, running, and goal times for nine-trial blocks in acquisition and three-trial blocks in extinction were transformed into logs [base e of $(X+1)]$. Repeated-measures analyses of variance (ANOVA) over the final four blocks of acquisition indicated that asymptotic performance was reached by all groups in all three measures. Trial-by-trial comparisons indicated no differences in running time for $\mathbf{R}$ and $\mathbf{N}$ trials. Also, there were no significant differences between groups (all Fs $<1$ ) or interactions.

For Day 1 of extinction, ANOVAs indicated increases in latency in starting $(F=6.13$, df $=5 / 275, p<.001)$, running $(F=25.40, p<.001)$, and goal sections $(F=12.14, p<.001)$. However, significant differences between groups were found only in the goal section $(F=5.59$, df $=4 / 55$, $\mathrm{p}<.001$ ); th is data is illustrated in Fig. 1. A Newman-Keuls test showed that latencies for the CR groups were equal to one another and significantly greater than latencies for the PR groups which were also equal to one another.

For Day 2 of extinction, comparisons on the first block yielded no initial differences between groups in any section of the alley. ANOVAs over the entire second day indicated significant increases in latency over blocks in starting ( $F=12.05$, $\mathrm{df}=5 / 275, \mathrm{p}<.001)$, running $(F=4.20$, $p<.001)$, and goal measures $(F=6.83$, $\mathrm{p}<.001)$. Again, the PR groups were equal but more resistant to extinction than the $C R$ groups in the goal section $(F=4.35$, $\mathrm{df}=4 / 55, \mathrm{p}<.005)$. A Newman-Keuls test localized this difference and also showed that Group 5 (R R R) was more resistant to extinction than Group $4(R+R+R+)$.

\section{DISCUSSION}

The present results indicate 90 acquisition trials of small reward magnitude were sufficient to produce PRE. The finding that $P R$ groups did not extinguish as rapidly as $\mathrm{CR}$ groups is consistent with results from previous replacement studies using large magnitude and extended training. Under present conditions, however, PRE was obtained only in the goal section of the alley.

Since no differences were obtained in extinction between PR groups, the degree of replacement ITR did not appear as a crucial variable for PRE under the present small magnitude conditions. Consequently, a discrimination explanation, suggesting little or no ITR interference with $\mathrm{N}$-length, would be favored over a frustration explanation (Lobb \& Runcie, 1967) since equal PRE was obtained both for Ss receiving ITR following every $\mathrm{N}$-trial (Group 3: $\mathrm{N}+\mathrm{N}+\mathrm{N}+$ ) and for $\mathrm{Ss}$ receiving only a single ITR after each N-length sequence (Group 1: N N N+).

It would seem the terminal response $\left(R_{T}\right)$ established by ITR placements (Capaldi \& Wilson, 1968) did not achieve sufficient strength to produce differential PRE for the PR groups in the present study. However with more training or larger reward magnitude, differences between PR groups would be expected since the N-lengths conditioned to $\mathrm{R}_{\mathrm{T}}$ differed for each $\mathrm{PR}$ group. $^{3}$

The fact that ITR during CR appeared to facilitate extinction would be expected if it is assumed that ITR following R-trials

\section{FRED P. VALLE, University of British Columbia, Vancouver, Canada}

In a recent article, Jensen (1968) reported that the weight curve of rats maintained entirely on Noyes pellets was parallel to that of rats maintained, primarily, on Purina chow. Jensen concluded that Purina chow and Noyes pellets are nutritionally equivalent.

Jensen's conclusion is supported by the actual caloric estimates given for the two diets: (1) Williams (1968) reported a caloric value of $4.4 \mathrm{kcal} / \mathrm{g}$ for Purina chow on the increases magnitude of reward. Here. however, the ITN placement procedure during extinction may be a more probable reason for greater extinction of Group 4 $(\mathrm{R}+\mathrm{R}+\mathrm{R}+)$ on Day 2

\section{REFERENCES}

BLACK, R. W., \& SPENCE, K. W. Effects of intertrial reinforcement on resistance to extinction following extended training. Journal of Experimental Psychology, 1965, 70, 559-563.

CAPALDI, E. J., HART, D., \& STANLEY, L. R. Effect of intertrial reinforcement on the aftereffect of nonreinforcement and resistance to extinction. Journal of Experimental Psychology, 1963, 65, 70-74.

CAPALDI, E. J. Partial reinforcement: A hy pothesis of sequential effects. Psychological Review, 1966, 73, 459-477.

CAPALDI, E. J., \& OLIVIER, W. P. Effect of intertrial reinforcement following a substantial number of consistently rewarded trials. Journal of Experimental Psychology, 1967, 75 135-138.

CAPALDI, E, J., \& WILSON, N. B. Intertrial reinforcement: A test of several hypotheses. Psychonomic Science, 1968, 13, 169-170.

LOBB, H., \& RUNCIE, D. Intertrial reinforcement as interference with consolidation. Psychonomic Science, 1967, 9, 25-26.

SPENCE, K. W., PLATT, J. R., \& MATSUMOTO $R$. Intertrial reinforcement and the partial reinforcement effect as a function of number of training trials. Psychonomic Science, 1965 , 3, 205-206.

\section{NOTE}

1. This research was supported by National Institute of Mental Health Fellowship F1-MII-556-02 to the first author. Gratitude is extended to Jean Barnes McGovern for her invaluable advice throughout the study.

2. Now at Kansas State College.

3. Capaldi, E. J., personal cominunication.

\title{
A note on the caloric values of Purina chow and Noyes pellets
}

basis of information supplied by the Ralston Purina Company. (2) In February 1968, I received the following information from Mr. J. E. Brown of the P. J. Noyes Company: The caloric value of standard formula Noyes pellets is $4.34 \mathrm{kcal} / \mathrm{g}$.

\section{REFERENCES}

JENSEN, G. D. Operant performance as a function of novelty of reward. Psychonomic Science, $1968,12,221-222$.

WILLIAMS, R. A. Effects of repeated food deprivations and repeated feeding tests on feeding behavior. Journal of Comparative \& Physiological Psychology, 1968, 65, 222-226. 